\title{
Scheduling for Indonesia's Aircraft Wing Structure Design Project with Critical Path Method and Resource-Constrained Project Scheduling
}

\author{
Melissa Putri Hidayat, M. Dachyar*, and Farizal \\ Industrial Engineering Department, Universitas Indonesia
}

\begin{abstract}
As an archipelagic country, Indonesia has high needs for its aviation development. About 270 million people are predicted to fly from and within Indonesia in 2034, which is three times larger than current market conditions. Due to the complexity of aircraft development projects, management of a well-designed Indonesian aircraft design project needs to be implemented. This research aims to analyze the scheduling of aircraft wing structure design project made in Indonesia. Critical Path Method (CPM) and Resource-Constrained Project Scheduling (RCPS) are used to get better scheduling with a shorter duration to complete the project. Results from resource allocation using RCPS can yield a shorter project duration (730 working days) compared to the company's normal resource allocation (950 working days).
\end{abstract}

\section{Introduction}

Indonesia can be regarded as a highly developed market for air travel. This can be seen from the $28.4 \%$ increase of air transportation passengers from 27,421,235 passengers in 2009 to $96,529,128$ passengers in 2016 [1]. Indonesia's domestic flights are ranked fourth in the world for the growth of the aircraft passenger market with an increase of $14.3 \%$ in 2016 [2].

Each project has different constraints. However, there are some general limitations in project management, such as quality, scope, scheduling, resources, budget, and risks. Through these project management constraints, the viability of a project can be analyzed [3].

Aircraft development projects are complex. Based on the PMI report, 50\% of aviation projects experience delays [4]. Therefore, management of a well-designed Indonesian aircraft design project is necessary.

\section{Literature Review}

Project management is the application of knowledge, skills, tools, and techniques to meet project needs. Project management can be done with the appropriate application and

* Corresponding author: mdachyar@yahoo.com 
integration of the process in the project to execute it effectively and efficiently [3]. Implementation of project management can be done by various methods, such as using the conventional method like Critical Path Method [5], Program Evaluation Review Technique [6], or alternative methods like Critical Chain Method [7], Business Process Reengineering [8], and various other methods.

Critical path is the path of activities sequences that determine the duration of the project. The purpose of the critical path is to identify the sequence of activities to be finished in time to achieve project deliverables [9]. Critical Path Method (CPM) is used for all project types, such as construction, facility maintenance, or software development [10].

Scheduling for projects with limited resources can be done with Resource-Constrained Project Scheduling (RCPS) to allocate resources to activities and obtaining the shorter duration of critical activity so that the project duration can be reduced after knowing the critical path from CPM method [11].

\section{Research Methodology}

\subsection{Data Collection}

Duration and dependency relationship between each activity are collected so activity could be scheduled. In this project, there are 59 activities to achieve project deliverables.

This project has ten human resources with the same competence and qualifications to be able to work on all activities on the aircraft wing design project. Based on company's normal allocation, resource allocation for each activity is carried out based on at the duration length for each activity. Shorter duration of activity means fewer workers are allocated. Conversely, the longer the duration of the activity, the more workers that should be allocated to the activity.

Table 1. Company's Normal Resource Allocation

\begin{tabular}{|c|c|}
\hline Activity Duration & Num. of Resources \\
\hline$>=2240$ hours & 5 people \\
\hline$>=1600$ hours & 4 people \\
\hline$>=960$ hours & 3 people \\
\hline$>=320$ hours & 2 people \\
\hline$<320$ hours & 1 people \\
\hline
\end{tabular}

\subsection{Project Scheduling Results with Critical Path Method}

Critical Path Method (CPM) is used to find the critical path that exists in the project. Scheduling of resources is carried out with Microsoft Project software. At first, the resources are allocated according to the normal resource allocation set by the company in Table 1. By allocating resources based on company's normal allocation, the total duration of the project is 950 working days as shown in Fig. 1 .

Project duration could be shortened by allocating more resources to activities that are on a critical path so that the overall duration of the project can be shortened by the ResourceConstrained Project Scheduling (RCPS) allocation. By prioritizing resources on activities that are on a critical path, the duration of the critical activities will be shorter, which results in a shorter duration of the project. The overall duration of the project after allocating resources with RCPS is 736 working days as shown in Fig 2. 


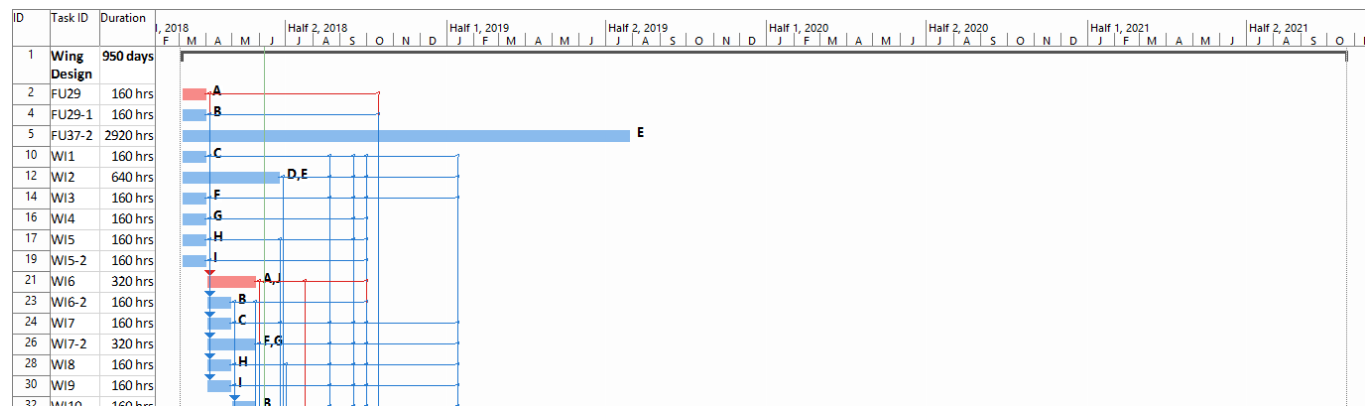

Fig. 1. Part of Gantt Chart for Project Scheduling with Company's Normal Allocation

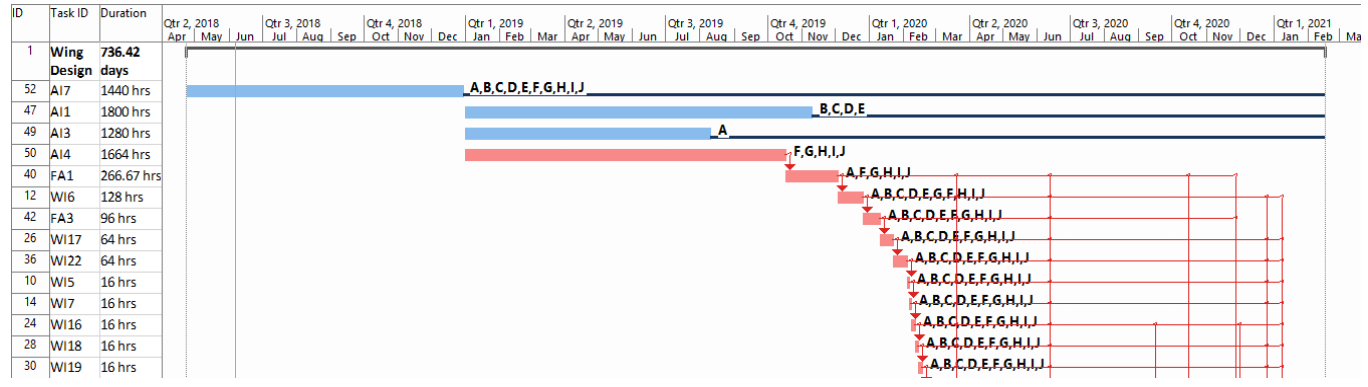

Fig. 2. Part of Gantt Chart for Project Scheduling with RCPS

\section{Results and Discussion}

Each project has different constraints. However, there are some general limitations in project management, such as scheduling, resources, budget, and risks. Through these constraints, the viability of a project can be analyzed [3].

\subsection{Resources and Scheduling}

By looking at the critical paths of the project, a resource could be allocated better with RCPS allocation. Activities that are on critical paths are the primary focus for resource allocation. Several activities also have higher priority for the RCPS allocation [11].

It was found that there is a reduction in the duration of the project by 214 working days from the normal resource allocation compared to the allocation of resources with RCPS. The project duration with RCPS allocation is 736 working days.

The CPM method with RCPS allocation takes account of the resource limitations as well as the duration of each activity in the allocation of its resources. It is suitable for the aircraft wing structure design project that has limited resources.

\subsection{Budget}

Budget to be spent by the company are viewed from the resources length of work. Longer working hours indicates that higher budget needs to be spent on the project.

The result shows that resource allocation on a critical path with RCPS did not change the total working hours of the resource compared to the company's normal resource allocation. Working hours of the resource with critical path allocation have a range of 4,700-5,900 hours. Working hours for resources with normal allocation has a range of 4,300-6,880 hours. From 
the results, it could be seen that the division of work for each resources using RCPS is more evenly distributed than the company's normal allocation as shown in Table 2.

Table 2. Working Hours for Each Resource

\begin{tabular}{|c|c|c|}
\hline Resource & $\begin{array}{c}\text { Working hours with normal } \\
\text { allocation (hours) }\end{array}$ & $\begin{array}{c}\text { Working hours with RCPS } \\
\text { allocation (hours) }\end{array}$ \\
\hline Resource 1 & 6.360 & 5.526 \\
\hline Resource 2 & 4.300 & 5.360 \\
\hline Resource 3 & 4.660 & 4.920 \\
\hline Resource 4 & 4.770 & 5.516 \\
\hline Resource 5 & 4.760 & 5.385 \\
\hline Resource 6 & 6.880 & 5.675 \\
\hline Resource 7 & 6.840 & 4.758 \\
\hline Resource 8 & 4.400 & 4.748 \\
\hline Resource 9 & 5.840 & 5.399 \\
\hline Resource 10 & 4.300 & 5.825 \\
\hline Totals & 53.110 & 53.110 \\
\hline
\end{tabular}

\subsection{Risk}

The sequence of project activities depends on the relationship between activities (predecessor and successor). Critical paths have an important role in the duration of the project with CPM method. The longer and the higher number of critical paths in a project, the greater the risk of the project. The project risk is shown from the stability of project duration. The longer and larger the number of critical paths, the greater the likelihood of adding to the overall duration of the project due to the activities on the critical path that might be delayed.

Table 3. Critical Path Comparison Results

\begin{tabular}{|c|c|c|}
\hline Resource Allocation & Critical Path & Critical Activity \\
\hline Normal & 3 Critical Path & 8 Activities \\
\hline RCPS & 67 Critical Path & 23 Activities \\
\hline Difference & 63 Critical Path & 15 Activities \\
\hline
\end{tabular}

Resource allocation affects the path and critical activities of the project. The risks of the design of aircraft wing structure project become higher when resources are allocated by RCPS method as shown in Table 3. Special attention from the company is required in carrying out the project if the resource allocation is done with RCPS allocation.

To avoid unpredictable additional duration of the project, the company can make regular scheduling improvements to ensure the current conditions of the project. By regularly scheduling the design activities, company found the best sequence of activities, duration of the project, allocation of resources, and the estimated costs to be spent.

\section{Conclusion}

Project management for the design of aircraft wing structure made in Indonesia with CPM using RCPS allocation resulted in a shorter duration (736 working days) compared to the company's normal allocation without using RCPS (950 working days). Risk of unpredictable delay from the project using RCPS allocation will increase compared to the normal allocation scheduling of the company. Addition of activity on the critical path can increase the overall project duration in case of delays happened on activity completions.

This research is funded by Universitas Indonesia - PITTA 2018 


\section{References}

1. The World Bank, (2016). [Online]. Available:

https://data.worldbank.org/indicator/IS.AIR.PSGR?end=2016\&locations $=$ ID\&start $=200$ 9.

2. IATA, Annual Review (2017)

3. Project Management Institute, A Guide to the Project Management Body of Knowledge (PMBOK® Guide), (2017)

4. K. Venema and A. Gueniche, Benef. Microbes, 5, 97-98, (2014)

5. S. Zareei, Renewable and Sustainable Energy Reviews, 81, 756-759 (2018)

6. G. Bergantiños, A. Valencia-Toledo, and J. Vidal-Puga, Discret. Appl. Math., 243, 1120 (2018)

7. A. Izmailov, D. Korneva, and A. Kozhemiakin, Procedia - Soc. Behav. Sci. 235, 189197 (2016)

8. M. Dachyar and Z. A. H. Sanjiwo, Indian J. Sci. Technol., 11, 1-8 (2018)

9. C. Carson, P. Oakander, and C. Relyea, CPM Scheduling for Construction: Best Practices and Guidelines (2014)

10. J. Kim, C. Kang, and I. Hwang, Int. J. Proj. Manag., 30, 264-272 (2012)

11. J. R. Meredith and S. J. Mantel, Project management - A managerial approach, (2009) 